\title{
Experiments on Strategic Choices and Markets
}

\author{
Wilfred Amaldoss, Teck-Hua Ho, Aradhna Krishna, \\ Kay-Yut Chen, Preyas Desai, Ganesh Iyer, Sanjay Jain, Noah Lim, John Morgan, Ryan \\ Oprea, and Joydeep Srivasatava ${ }^{1}$
}

\begin{abstract}
Much of experimental research in marketing has focused on individual choices. Yet in many contexts, the outcomes of one's choices depend on the choices of others. Furthermore, the results obtained in individual decision making context may not be applicable to these strategic choices. In this paper, we discuss three avenues for further advancing our understanding of strategic choices. First, there is a need to develop theories about how people learn to play strategic games. Second, there is an opportunity to enrich standard economic models of strategic behavior by allowing for different types of bounded rationality and by relaxing assumptions about utility formulation. These new models can help us to more accurately predict strategic choices. Finally, future research can improve marketing practice by designing better mechanisms and validating them using experiments.
\end{abstract}

February 5, 2008

\footnotetext{
${ }^{1}$ Wilfred Amaldoss is Associate Professor of Marketing, Duke University, Teck-Hua Ho is William Halford Jr. Family Professor of Marketing, University of California at Berkeley, Aradhna Krishna is Isadore and Leon Winkelman Professor of Marketing, University of Michigan, Kay-Yut Chen, HP Labs, Palo Alto, Preyas Desai is Professor of Marketing, Duke University, Ganesh Iyer is Edgar F. Kaiser Professor of Marketing, University of California at Berkeley, Sanjay Jain is Professor of Marketing at Texas A\&M University, Noah Lim is Assistant Professor of Marketing, University of Houston, John Morgan is Gary and Sherron Kalbach Professor of Economics at University of California at Berkeley, Ryan Oprea is Assistant Professor of Economics at University of California at Santa Cruz, and Joydeep Srivastava is Associate Professor of Marketing, University of Maryland.,
} 


\section{Introduction.}

Most of the experimental research in marketing has focused on individual choices (see for example Simonson and Tversky, 1992; Payne, Bettman, and Johnson, 1993). However, in many situations the outcomes of one's choices depend on the choices made by others. Similarly, most firms operate in a competitive environment where managers must consider strategic interaction among firms in choosing among their marketing-mix alternatives. This strategic interdependence raises many fundamental research questions that are absent in individual choice literature (we discuss some of them below). Moreover, results on individual decision making may not hold in strategic contexts. For example, consider a network of roads. Typically, adding a connecting road to a preexisting network reduces congestion and travel time. However, when commuters are strategic in their route choice in some circumstances this additional road could actually increase travel time, (Braess 1968). As Morgan, Sefton, and Orzen (2007) demonstrate, this is not just a theoretical possibility. In controlled laboratory experiments, adding a connecting road changes commuter behavior so as to increase everyone's travel time. The purpose of this article is to show the importance of and encourage the use of experiments (both laboratory and field) to study strategic choices, since they are useful for testing theory and also for addressing real-world problems.

While research in marketing is very rich in "models of markets" and "models of strategic choices”, causal tests of these theoretical models have been quite limited and support for these models has generally been offered by showing consistency between one or more model implications and empirical findings in field settings. In contrast, 
experimentation makes it possible to exercise control over the independent variables and perform a clean test of theory. In addition, these theoretical models rely critically on several key assumptions, which have not been subjected to rigorous empirical tests until recently. Thus formal tests of these assumptions are useful for providing a solid empirical foundation for the entire field.

Marketing is inherently an applied field; hence it is important to provide a constant dialogue between experimenters and practitioners. Experimentation provides one such avenue since one can create experimental conditions that closely resemble the environment in the field. This kind of experimental test-bedding offers us the opportunity to refine our theory and bring it closer to practice.

In this paper, we describe three ways to test and extend the standard theoretical models:

1. A stylized fact in experimental research is that people initially deviate from equilibrium predictions but converge to them over time (e.g., Camerer, 2003). This empirical regularity has initiated the development of theories about how people learn to play strategic games (e.g., Camerer and Ho 1999, McKelvey and Palfrey 1995).

2. Subjects frequently do not attain equilibrium even after repeated play. This observation has motivated theorists to enrich standard economic models by allowing for different types of bounded rationality and by relaxing assumptions about utility formulation. These new models allow us to more accurately predict strategic choices. 
3. A simple but powerful way of checking whether the standard models have external validity is to test them in practically relevant contexts. Such experimental tests entail understanding the institutional details embedded in a practical context and allow the experimenter to study how these institutional details can influence the predictive power of the models.

Consequently, we divide this article into three sections, namely, Learning (Section 2), Theory development informed by experiments (Section 3), and Designing new mechanism and studying strategic choices (Section 4). In Section 2, we discuss how theories of learning can better account for experimental data about strategic choice. In Section 3, we discuss a few models that account for boundedly rational behaviors observed in experiments. In Section 4, we provide an overview of experimental research on mechanisms designs and research formulated for practitioners. The mechanism design work that is discussed pertains to Business-to-Business procurement, Time-Share condos, MBA Bidding Systems and Kidney Transplants. Co-operative advertising work we discuss focuses on retailer advertising and on the National Dairy Board advertising ("got milk?”).

\section{Learning.}

Economic experiments on strategic games typically generate data that, in early rounds, violate standard equilibrium predictions. However, subjects normally change their behavior over time in response to experience. The study of learning in games is about how this behavioral change works empirically. This empirical investigation also has a theoretical payoff: If subjects' behavior converges to an equilibrium, the underlying learning model becomes a theory of equilibration. In games with multiple equilibria, this 
same model can also serve as a theory of equilibrium selection, a long-standing challenge for theorists. There are two general approaches to studying learning: Population models and individual models.

Population models make predictions about how the aggregate behavior in a population will change as a result of aggregate experience. For example, in replicator dynamics, a population's propensity to play a certain strategy will depend on its 'fitness' (payoff) relative to the mixture of strategies played previously (Friedman, 1991; Weibull, 1995). Models like this submerge differences in individual learning paths.

Individual learning models allow each person to choose differently, depending on the experiences each person has. For example, in Cournot dynamics, subjects form a belief that other players will always repeat their most recent choice and best respond accordingly. Since players are matched with different opponents, their best responses vary across the population. Aggregate behavior in the population can be obtained by summing individual paths of learning. Next we discuss two important individual learning models.

Experience-Weighted Attraction (EWA) Learning. One of the leading individual learning models is the experience-weighted attraction learning (Camerer and Ho, 1999 and Ho, Chong and Camerer, 2007). This approach nests classical reinforcement learning and belief learning (including Cournot and weighted fictitious play). The model strives to explain, for every choice in an experiment, how that choice arose from players' previous behavior and experience. The EWA model assumes strategies have numerical evaluations, which are called "attractions". Learning rules are denoted by how attractions are updated in response to experience and how total level of experience accumulates. 
Attractions are weighted by experience and then mapped into predicted choice probabilities for strategies using some well-known statistical rule (such as logit). Empirical tests run on dozens of studies observations spanning a wide class of games show that EWA model fits and predict behavior out-of-sample and out-of-game better than the reinforcement and belief learning models.

Most learning models assume players are adaptive (i.e., they respond only to their own previous experience and ignore others' payoff information) and that their behavior is not sensitive to the way in which players are matched. However, here are subjects who can anticipate how others learn and choose actions to influence others' path of learning in order to benefit themselves. Camerer, Ho, and Chong (2002) propose a generalization of these adaptive learning models to allow this kind of sophisticated behavior. This generalized model (called sophisticated EWA model) assumes that there is a mixture of adaptive learners and sophisticated players. An adaptive learner adjusts his behavior according to one of the above learning rules. A sophisticated player does not learn and rationally best-respond to his forecast of others' learning behavior. This model, therefore, allows "one-stop shopping" for investigating the various statistical comparisons of learning and equilibrium models.

We believe the adaptive and sophisticated EWA models can be part of the standard tool kit for marketing scientists (Amaldoss and Jain 2002 and 2005a). Since these models assume less rationality on players and are generalizations of standard equilibrium models, they may yield new insights and generate new predictions that standard models could not do. One area where these learning models could be fruitfully applied is in durable goods markets. Unlike perishable products, durable goods last for 
several periods. Consequently, both consumers and firms need to form expectations about likely future behavior of each other and these models can be applied in such contexts (e.g., Desai, Koenigberg and Purohit 2004, Bruce et al 2006, see also Cripps and Meyer 1994).

Directional Learning. An important alternative to reinforcement learning models are directional learning models first proposed by Selten and Stoecker (1986) and developed in Selten and Buchta (1994). The idea is often illustrated with a simple example. Suppose an archer fires an arrow at a target and misses, firing too far to the left. On her next try, the archer will probably aim a bit more to the right. If the archer now fires too far to the right she will make a similar adjustment to the left. The simplest directional learning models predict just such qualitative behavior in games with strategy spaces defined on a line. More complicated models make quantitative predictions, often based on the idea that adjustments will be increasing functions of ex post error. To return to the archer analogy, one might expect the magnitude of the archer's adjustment to be larger the further the archer's arrow lands from the target.

Directional learning models differ from EWA and its relatives in two primary ways. First, directional learning models are exclusively concerned with strategy spaces defined on real lines whereas most other learning models tend to be applied to unordered strategy spaces, typically discrete. Second, unlike EWA, choice probabilities in directional learning do not depend explicitly on the relative payouts of the entire ex post menu of strategies. Instead, directional learning posits choice probabilities based exclusively on the relationship between the agent's latest strategy and the ex post optimum. In qualitative versions of the theory this collapses to a simple prediction that 
the probability that the next choice will be in the direction of the ex post optimum is greater than 0.5. In quantitative versions studied more recently, directional learning models generate a noisy (and unimodal) estimate of an agent's next strategy determined by the location of the current strategy on the strategy line and some increasing function of its distance from the optimum. A corollary is that directional learning predictions are always Markovian, depending entirely on the latest period's decisions and outcomes.

There is evidence that directional learning models improve upon alternative theories of adjustment in some experimental settings. Mitzkewitz and Nagel (1993) show that behavior in repeated ultimatum games can be explained using directional learning while Roth and Erev (1995) show that the results can also be rationalized using reinforcement learning models. Grosskoff (2003) argues that while reinforcement and directional learning approaches are difficult to distinguish in traditional ultimatum games, they generate quite distinct predictions in multilateral versions of the game. Experimental evidence in fact favors directional learning over reinforcement-type models in this setting. Based on observable similarities between decision making in multilateral versus traditional ultimatum games, Grosskoff conjectures that behavior in repeated traditional ultimatum games is best described by directional learning models. Nagel (1995) studies strategy choices in a repeated experimental guessing game and argues that directional learning theory improves upon bounded rationality theories in explaining adjustments over time. Cachon and Camerer (1996) find further evidence in support of a type of directional learning in coordination game settings that they call "loss avoidance" in experimental median effort games. Nagel and Tang (1998) compare the explanatory power of several learning models on behavior in a repeated normal form centipede games 
and find that intertemporal strategy changes in their data are better explained by directional learning than the alternative reinforcement and belief models they test.

Because they focus on strategies on lines, directional learning models are natural fits to market and auction experiments in which prices or quantities are the main strategic variables. Kagel and Levin (1999) show that directional learning can account for the pattern of bid adjustments made by insiders in common value auctions. Selten, Abbink and Cox (2005) show that more than half of the subjects in winner's curse experiments adapt their decisions over time using directional learning. Neugebauer and Selten (2006) argue that directional learning theory can help explain tendencies to overbid in first-price sealed bid auctions. Nagel and Vriend (1999) find evidence that subjects engage in directional learning when making production decisions in large world oligopoly environment. Huck, Normann and Oechssler (1999) study learning dynamics in Cournot markets, finding that while learning direction theory has some explanatory power, no learning model tested could entirely account for quantity dynamics. Cason and Friedman (1998) use a structural quantitative directional learning model to explain bidding behavior in stochastic experimental call market.

What predictions do directional learning models yield? In strategic settings, directional learning may converge on efficient Nash outcomes but need not. Anderson, Holt and Goeree (2004) show that if agents implement directional learning imperfectly, with errors that increase in ex post losses, behavior converges to a continuous quantal response equilibrium. AHG also show that this equilibrium is stable under a number of frequently studied experimental environments. Thus directional learning theory may serve as a micro foundation for one of the key tools in behavioral game theory. Oprea, 
Friedman and Anderson (2007) study an individual decision task in which loss functions are indeed asymmetric and find that subjects use adjustment parameters that are correspondingly asymmetric and therefore lead to behavior which is close to optimal. The well tuned adjustment parameters observed in OFA suggest that subjects may in fact engage in a form of meta-learning in which adjustment parameters are themselves learned as subjects acquire knowledge of symmetries in the payoff function.

\section{Theory development informed by experiments.}

Nash equilibrium assumes that players form mutually consistent beliefs about other players and take decisions without any error. Experimental evidence suggests that human decisions are noisy and furthermore there is substantial heterogeneity in behavior of players. In response to these findings, researchers have relaxed some of the restrictive assumptions of Nash equilibrium. In Quantal Response Equilibrium (QRE), players are allowed to make error prone strategy choices, and in Cognitive Hierarchy $(\mathrm{CH})$ model beliefs needs not be mutually consistent.

In marketing, we often use a logit model to allow for errors in consumer's product choices. The idea behind QRE is very similar to the idea of incorporating errors in the product choices of individual consumers (McKelvey and Palfrey 1995). As is the case of for logit models, the more attractive a strategy the more likely a player chooses that strategy. Note, however, that unlike individual consumer choice models (logit formulation), we need to incorporate players' beliefs about the actions of the other players in a strategy choice model. Hence, as in the case of Nash equilibrium, QRE assumes that the beliefs are mutually consistent in equilibrium and we solve for a fixed point in choice probabilities. QRE has the attractive property that it is a generalization of 
the Nash equilibrium and converges to the Nash equilibrium as the error in choices vanishes.

Furthermore, QRE can generate predictions that differ sharply from Nash equilibrium and fit the observed data more closely. For instance, Baye and Morgan (2004) study QRE in simple Bertrand games—games where the unique Nash equilibrium is for all firms to charge marginal cost. In QRE of such games, firms consistently price above marginal cost, and the market exhibits considerable price dispersion. Competition produces Cournot-like outcomes under QRE—firm profits decline in the number of competitors. Unlike the Bertrand-Nash predictions, these features fit well with data from controlled laboratory experiments. Prices are dispersed and above marginal cost in these experiments, and profits decline with number of competitors.

An alternative approach to allow for bounded rationality in strategic settings is to relax mutual consistency in the beliefs of players. The $\mathrm{CH}$ model assumes that players engage in iterative step-by-step reasoning (Camerer et al. 2004). The iterative process starts with zero-step thinkers who make random choices. The one-step thinkers best respond to zero-step thinkers. In general, $k$-step thinkers assume that their opponents are distributed over zero to $k$ - 1 steps. Thus the $k$-step players fail to see the possibility that others could think with as many steps as they do, if not more. Note that if all players have $k=\infty$, then the model reduces to the Nash equilibrium model. Camerer and Ho propose that $k$ can be distributed according to a poisson distribution. The model has been successfully applied to account for behavior in several strategic contexts (see for Camerer et al. 2004). 
While the QRE and $\mathrm{CH}$ model relax some critical assumptions of Nash equilibrium, they still do not account for the possibility that an individual's choices may be guided by factors other than their own preferences. For example, it is generally accepted that the decision to purchase a "conspicuous” product depends not only on the material needs satisfied by the product, but also on social needs such as prestige (see for example Belk 1988). Amaldoss and Jain (2005a) capture such social desires by allowing the utility derived from a product to depend on consumption externality.

In their model snobs are consumers whose utility from a product decreases as more people consume the same product. In a similar fashion, they define followers as consumers whose utility from a product increases as more people consume the product (Ross, Bierbrauer and Hoffman 1976, Jones 1984, also see Becker 1991 for a similar formulation). Their theoretical analysis of a monopoly model suggests that if the market is comprised of only snobs or followers, then consumers would not demand more as price increases. However, if the market is comprised of both snobs and followers, then more snobs might buy as price increases. Corroborating evidence for these results is found in an empirical study of visible status goods purchased by women (Chao and Schor 1998). Consistent with the model, experimental investigation shows that more snobs buy as price rises, even though the products have neither quality differences nor any signal value. Furthermore, they find some support for the rational expectations framework at the aggregate level. An analysis of the first trial data shows that subjects' behavior is qualitatively consistent with model predictions. They fitted the $\mathrm{CH}$ model on the experimental data and find that on average subjects were probably capable of three to four steps of iterative reasoning. 
On generalizing the analysis to a duopoly, they show that while the desire for exclusivity leads to higher prices and firm profits, a desire for conformity leads to lower prices and profits (Amaldoss and Jain 2005b). Their results show that consumers purchase high quality products not because of their desire for exclusivity, but despite it. In a laboratory test, they find support for the claim that demand for a product among consumers who desire exclusivity might increase as its price increases.

Another interesting social phenomenon is reference groups. Consumer's evaluation of product and brand evaluations are influenced by these reference groups, especially when the product is a publicly consumed luxury good. Marketers of such luxury goods need to carefully balance two important social forces: the desire of leaders to distinguish themselves from followers and the countervailing desire of followers to assimilate with leaders. Amaldoss and Jain (2007a) show that the presence of reference group effects can motivate firms to add costly features which provide limited or no functional benefit to consumers. Furthermore, reference group effects can induce product proliferation on one hand and motivate firms to offer limited editions on the other hand. They find that offering a limited edition can increase sales and profits. In some cases reference group effects can even lead to a buying frenzy. Amaldoss and Jain (2007b) present experimental support for this analysis.

It is well established that consumer memory is limited. For instance, consumers may have bounded recall and may recall prices only as categories (Dow 1990, Chen, Iyer and Pazgal 2007). Now researchers have begun to explore the strategic implications of such cognitive limitations. Chen et. al (2007) show that in competitive markets small amounts of initial increases in the number of recall categories lead to market outcomes 
which are very close to that in the full recall equilibrium. Thus there is a suggestion that market competition may adjust to the cognitive limitations of consumers. Another form of bounded consumer rationality might arise from information processing constraints. For example, consumers may be unable to distinguish between the true quality offered by firms from other environmental variables like retail store atmosphere. Iyer and Kuksov (2007) study the implications of this deficiency in information processing. They show that, even if consumers are rational in their inference strategies, a firm would still have the incentive to supply store environmental factors despite the fact that they do not increase consumer utility.

\section{Designing new mechanisms and studying strategic choices.}

One area of research within experimental economics of particular relevance to marketing is that of market design, or more specifically "mechanism design” where one designs mechanisms in such a way that they are incentive compatible and modify behavior to achieve the desired outcomes. Certain types of problems have received a lot of academic attention within this area, e.g., matching problems and public goods problems.

Matching problems involve scarce resources being matched to agents based on their preferences; in two-sided matching problems, resources also have preferences over agents. One of the most widely used matching models is due to Gale and Shapley (1962), known as the marriage model or two-sided matching model where firms and workers are matched with each other using preferences of firms over workers and of workers over firms. A well known one-sided matching problem is the house-allocation problem or 
assignment of dorm rooms to students, where the solution concept of random serial dictatorship (order students by a lottery and let them take their pick in order of the lottery) has often been used, but more efficient concepts have recently been proposed using variants of the Top-Trading-Cycle mechanism (e.g., Abdulkadiroglu and Sonmez 1999).

Some of these matching mechanisms have been put into practice. For example, the hospital-intern matching mechanism (Roth and Peranson 1997) was adopted in 1997 by the National Resident Matching Program, fourteen transplant centers in New England plan to implement the economists' design for kidney exchanges (Roth, Sonmez and Unver 2004; see also Krishna and Wang 2007), and the Boston and New York Public schools have changed their admission procedure based on recently proposed mechanism designs (Chen and Sonmez 2002).

Many mechanisms are relevant to the business world and that have been studied by researchers in marketing. Wang and Krishna (2006) apply mechanism design to the timeshare industry, where members own timeshare "weeks" and can exchange these weeks amongst themselves without money so as to better match their preferences and thus increase efficiency. They demonstrate theoretically that the two major timeshare exchange mechanisms used currently can cause efficiency loss and propose an alternate exchange mechanism. The proposed mechanism is shown to be Pareto-efficient, individually-rational, and strategy-proof. An individually-rational mechanism assures every member an alternative that is at least as good as the one she started with; a mechanism is strategy-proof (or dominant strategy incentive compatible) if no member can ever benefit by misrepresenting her preferences. The three exchange mechanisms are 
tested in laboratory experiments where exchange markets are simulated with networked “timeshare members". The results of the experiments are robust across four different environments and strongly support the theory.

Krishna and Unver (forthcoming), study the problem of allocation of course seats to students, which is a variant of the house allocation problem. Course allocations in Stanford Graduate School of Business School and Harvard Business School are done using variants of random serial dictatorship. As Krishna and Unver discuss in their paper, when bidding is used for course allocation, one can induce a two-sided matching market using student bids for each course as induced preferences of the courses, i.e., the courses are assumed to prefer students who bid a higher amount for them (Sonmez and Unver 2005). They test this alternate course allocation mechanism in a controlled field study and show that it outperforms the current system in terms of (Pareto) efficiency.

Mechanism design has also been used to motivate workers to exert the greatest effort. One incentive scheme (mechanism) commonly observed in practice is a tournament, in which workers are evaluated based on relative performance. Whether such a rank-order scheme elicits more effort than incentives tied to an individual's output falls under the domain of tournament theory (Lazear and Rosen 1981). A natural application of tournament theory in marketing is the design of sales contests. Kalra and Shi (2001) theoretically show that when salespeople are risk averse (as is commonly assumed in the sales force literature), winner-take-all contests or contests with multiple identical prizes are sub-optimal; contests that elicit the greatest effort have multiple prizes with unique rank-ordered prize values. The actual prize values in the optimal contest are also sensitive to the degree of risk aversion of salespeople. 
Lim, Ahearne and Ham (2007) test this theory in laboratory and field studies. They show that the winner-take-all contest yields lower sales effort versus a contest with multiple identical prizes and that the latter performs as well as the optimal structure with unique rank-ordered prizes, suggesting that having the optimal structure is not necessary.

There are many other questions about sales contests that remain unanswered. For instance: Should managers supply informational updates about the performance of other salespeople when the contest is taking place? How is the optimal prize structure of a sales contest affected by heterogeneous abilities in the sales force? We believe that economic experiments can yield significant insights to these questions.

Experimental research to test alternative supply chain mechanisms has also gained favor in recent years. The literature in experimental supply chain research is roughly divided into two areas. The first is the study of stocking decisions. Representative papers include Schweitzer and Cachon (2000) and Bolton and Katok (2006) which study behavioral issues associated with the newsvendor problem. Sterman (1989) and Croson and Donohue (2002) study the beer game. The focus is on how different behavioral effects such as learning or communication (in the case of the beer game) affect inventory decisions made by human decision makers. The second area is contracting between supply chain partners. Katok and Wu (2006) study behavioral effects on pricing contracts between a manufacturer and a supplier. Ho and Zhang (2006) show that theoretically equivalent contracts were not equivalent in human experiments. Ho and Lim (2007) study contracts with pricing blocks.

Chen, Kaya and Ozer (2007)'s experiments focus on the intersection of pricing, contracting and operations. They study a dual-channel scenario where a manufacturer 
contracts with a retailer but also competes with the retailer for customers who cares about the availability of products. They show that a game theory model can predict the direction of changes in subjects' decisions in response to the changes in the channel environment, but is less successful in predicting the actual decisions. Some unexplored issues in this area of research are inventory behavior under complex pricing contracts, pricing and inventory behavior in a dynamic setting, and trust in forecast commitments.

Besides academics, practitioners have started using experiments to design their policy decisions. For instance, Charness and Chen (2002) report the use of economic experiments to design minimum advertised policies for a major US manufacturer. Thus, both for academics as well as for practitioners in the business world, mechanism design offers many issues worth exploring. In another experimental research of practical significance, Oza and Srivastava (2007) examine the influence of environmental factors such as market trends (whether demand and profits are increasing versus declining) as well as solicitation appeals on individual members' contribution decisions for generic advertising. When members face a declining trend, for instance, marketing budgets are typically curtailed with the goal of conserving valuable resources. However, members may feel the urge to cooperate and increase their advertising budget in these tough market conditions (Krishnamurthy, Bottom, and Rao 2003). Effectiveness of different types of solicitation appeals varies with the market trend and this is explored in their research.

\section{Conclusion}

While the importance of strategic incentives for firm behavior has gained prominence in the theoretical marketing literature, experimental investigation in this area is only just beginning. The largest contributions to this area are unlikely to come from 
"off the shelf" theory models ported to a laboratory setting and then analyzed using static models. Rather, we think accounting for dynamic features, such as learning, and human features, such as mistakes, is essential for deepening understanding. Moreover, experiments in the lab and the field offer a chance to move beyond standard models - to investigate the behavioral impact of various market designs, and to add back some of the complexity and institutional richness that are often abstracted away for the sake of tractability in theory models. 


\section{References}

Amaldoss, W. and S. Jain (2002), “David versus Goliath: An analysis of asymmetric mixed strategy games and experimental evidence,” Management Science, 48 (8).

Amaldoss, W. and S. Jain (2005), “Conspicuous Consumption and Sophisticated Thinking,” Management Science, 51 (10), 1449-1466.

Amaldoss, W. and S. Jain (2005), "Pricing of Conspicuous Goods: A Competitive Analysis of Social Effects,” Journal of Marketing Research, 42, 30-42

Amaldoss, W. and Sanjay Jain, “Trading Up: A Strategic Analysis of Reference Group Effects.” Marketing Science, forthcoming.

Amaldoss, W. and Sanjay Jain (2007), “An Analysis of Limited Edition Products,” Working Paper. Marketing Department, Duke University.

Anderson, S., Goeree, J. and Holt, C. (2004), "Noisy Directional Learning and the Logit Equilibrium,” Scandinavian Journal of Economics, 106(3), 581-602.

Baye, M. and J Morgan (2004), "Price Dispersion in the Lab and on the Internet: Theory and Evidence” RAND Journal of Economics, Autumn 2004; 35(3): 449-66.

Berninghaus, S. and Ehrhart, K.M. (1998) “Time Horizon and Equilibrium Selection in Tacit Coordination Games: Experimental Results.” Journal of Economic Behavior and Organization, 37: 232-248.

Bettman, Jame, Mary Frances Luce and John Payne (1998), “Constructive Consumer Choice Processes.” Journal of Consumer Research, 25(3), 187-217.

Bolton, Gary and Elena Katok (2006), “Learning-by-doing in the newsvendor problem: A laboratory investigation of the role of experience and feedback”, Working Paper, Penn State University, University Park, PA.

Bruce, Norris, Preyas Desai and Richard Staelin (2005), “Trade Promotions of Consumer Durables.” Journal of Marketing Research, 42(1), 54-66.

Bruce, Norris, Preyas Desai and Richard Staelin (2006), “Enabling the Willing: Consumer Rebates for Durable Goods.” Marketing Science, 25(4), 350-366.

Cachon, G.P. and Camerer, C. (1996). “The Sunk Cost Fallacy, Forward Induction and Behavior in Coordination Games.” Quarterly Journal of Economics. 111, 165194. 
Camerer, C. and T-H Ho (1999), "Experience-Weighted Attraction Learning in Normal Form Games," Econometrica, 67, 837-874.

Camerer, C. Ho, T-H., and Chong, J-K., "Sophisticated Learning and Strategic Teaching," Journal of Economic Theory, 104 (2002), 137-188.

Camerer, C. F., T-H Ho, and J-K Chong (2004), "A Cognitive Hierarchy Model of Games," Quarterly Journal of Economics, 119 (3), 861-898.

Charness, Gary and Kay-Yut Chen (2002), "Minimum advertised price policy rules and retailer behavior: An experiment”, Interfaces, (32) 62-73.

Chen Yuxin, Ganesh Iyer and Amit Pazgal, "Limited Memory and Market Competition,” working paper, University of California, Berkeley.

Chen, Kay-Yut, Murat Kaya and Ozalp Ozer (forthcoming), "Dual Sales Channel Management with Service Competition," Manufacturing and Service Operation Management, special Issue on behavior research.

Chen, Yan and Tayfun Sonmez (2002), "Improving efficiency of on-campus housing: An experimental study”, American Economic Review, 92(5) 1669 - 1689.

Cripps, J. D., and Meyer, R. J., "Heuristics and Biases in Timing the Replacement of Durable Products," Journal of Consumer Research, 21 (2), 1994, 304-318.

Croson, Rachel and Karen Donohue (2002), "Experimental economics and supply chain management”, Interfaces, (32) 74-82.

Desai, Preyas, Oded Koenigsberg and Devavrat Purohit (2004), "Strategic

Decentralization and Channel Coordination.” Quantitative Marketing and Economics, 2(1), 5-22.

Erev, I. and Roth, A.E. (1998a). "Predicting How People Play Games: Reinforcing Learning in Experimental Games with Unique, Mixed Strategy Equilibria,” American Economic Review, 88(4), 848-881.

Friedman, D. "Evolutionary Games in Economics," Econometrica, Vol. 59, No. 3 (May 1991), 637-666.

Grosskopf, B. (2003) "Reinforcement and Directional Learning in the Ultimatum Game with Responder Competition,” Experimental Economics, 6:141-158 
Ho, T-H., Camerer, C. and Chong, J-K. "Self-tuning Experience-Weighted Attraction Learning in Games," Journal of Economic Theory, Vol. 133, no. 1, 177-198, 2007.

Ho, T-H. and Zhang, J-J, "Designing Price Contracts for Boundedly Rational Customers: Does the Framing of the Fixed Fee Matter?" Management Science, forthcoming.

Huck, S., Normann, H.-T., and Oechssler, J. (1999), "Learning in Cournot-OligopolyAn Experiment,” Economic Journal, 109(454), C80-95.

Iyer Ganesh and Dmitri Kuksov, "Consumer feelings and Equilibrium Product Quality,” working paper, University of California, Berkeley.

Kagel, J. and Levin, D. (1999), "Common Value Auctions with Insider Information." Econometrica," 67(5), 1219-1238.

Kalra, Ajay and Mengze Shi (2001), "Designing Optimal Sales Contests: A Theoretical Perspective,” Marketing Science, 20 (2), 170-193.

Katok, Elena and Diana Wu (2006), “Contracting in supply chains: A laboratory investigation”, Working Paper, Penn State University, University Park, PA.

Krishna, Aradhna and Yu Wang (2007), “The Relationship Between Top Trading Cycle and Top Trading Cycle and Chains Mechanisms," Journal of Economic Theory, January, Vol. 132, No. 1, 539-547.

Krishna, Aradhna and Utku Unver (forthcoming), "Efficiency Enhanced Course Bidding: Evidence from a Field Experiment at the University of Michigan Business School," Marketing Science.

Lazear, Edward P. and Sherwin Rosen (1981), "Rank-Order Tournaments as Optimum Labor Contracts,” Journal of Political Economy, 89 (5), 841-864.

Lim, Noah, Michael J. Ahearne and Sung H. Ham (2007), "Designing Sales Contests: Does the Prize Structure Matter?” Working paper, Department of Marketing, University of Houston.

Lim, Noah and Teck Ho (2007) "Designing Price Contracts for Boundedly Rational Customers: Does the Number of Blocks Matter?” Marketing Science, 26 (3), 312326.

Mitzkewitz, M. and Nagel, R. (1993), "Experimental Results on Ultimatum Games with Incomplete Information,” International Journal of Game Theory, 22, 171-198. 
Morgan, J., H. Orzen and M. Sefton (2007), "Network Architecture and Traffic Flows,” Working Paper, Haas School of Business, University of California, Berkeley.

McKelvey, R., and T. Palfrey (1995), “Quantal Response Equilibrium for Normal Form Games,” Games and Economic Behavior, 10, 6-38.

Nagel, R. and Tang, F.F. (1998). "Experimental Results on the Centipede Game in Normal Form: An Investigation on Learning.” Journal of Mathematical Psychology. 42, 356-384.

Nagel, R. and Vriend, N. (1999), “An Experimental Study of Adaptive Behavior in an Oligopolistic Market Game,” Journal of Evolutionary Economics, 9, 27-65.

Neugebauer, T., Selten, R. (2006), “Individual behavior of first-price auctions: The importance of information feedback in computerized experimental markets, Games and Economic Behavior, 54 183-204

Ockenfels, A. and Selten, R., (2005), "Impulse balance equilibrium and feedback in first price auctions," Games and Economic Behavior, vol. 51(1), pages 155-170.

Oprea, R., Friedman, D. and S. Anderson (2007), “Learning to Wait,: A Laboratory Investigation” mimeo.

Oza, Shweta and Joydeep Srivastava (2007), “Generic Advertising Campaigns: Effect of Market Trends and Solicitation Appeals on Voluntary Contributions,” Working Paper, Robert H. Smith School of Business, University of Maryland, College Park, MD.

Payne, J. W., Bettman, J. R., and Johnson, E. J., 1993, The Adaptive Decision Maker, Cambridge University Press.

Roth, A. and Erev, I. (1995) "Learning in Extensive-Form Games: Experimental Data and Simple Dynamic Models in the Intermediate Term.” Games and Economic Behavior, 1178-1184.

Roth, Alvin E. and E. Peranson (1997), “The effects of change in the NRMP matching algorithm,” Journal of the American Medical Association, September (3) 729-732. Roth, Alvin E., Tayfun Sonmez and M. Utku Unver (2004), “Kidney Exchange,” Quarterly Journal of Economics, 119(2) 457-488. 
Schweitzer, M. E., G. Cachon, (2000), “Decision bias in the newsvendor problem with a known demand distribution: Experimental evidence,” Management Science, 46 404-42.

Selten, R., Abbink, K., Cox, R. (2005), “Learning Direction Theory and the Winner’s Curse,” Experimental Economics, Volume 8, Number 1, April , pp. 5-20(16)

Selten, R. and Buchta, J. (1998). "Experimental Sealed Bid First Price Auction with Directly Observed Bid Functions.” In D. Budescu, I.E. and R. Zwick (eds.), Games and Human Behavior, Essays in Honor of Amnon Rapoport, Hillsdale, NJ.

Selten, R. and Stoecker, R. (1986), “End Behavior in Sequences of Finite Prisoner’s Dilemma Supergames: A Learning Theory Approach,” Journal of Economic Behavior and Organization, 7(1), 47-70.

Simonson, I. and A. Tversky (1992), "Choice in Context: Tradeoff Contrast and Extremeness Aversion,” Journal of Marketing Research, 29, 281-295.

Sönmez, Tayfun. And M. Utku Ünver (2005), “Course Bidding at Business Schools,” Boston College Working Papers in Economics, No 618.

Sterman, J. (1989), “Modeling managerial behavior: misperceptions of feedback in a dynamic decision making experiment,” Management Science, 35. 321-339.

Wang, Yu and Aradhna Krishna (2006), “Time-Share Allocations: Theory and Experiment”, Management Science, 52 (8), August, 1223-1238.

Weibull, J. Evolutionary Game Theory, MIT Press, 1995. 